\title{
Burnout among clinical dental students at Jordanian universities
}

D.H. Badran, ${ }^{7}$ M.H. Al-Ali, ${ }^{2}$ R.B. Duaibis ${ }^{2}$ and W.M. Amin ${ }^{2}$

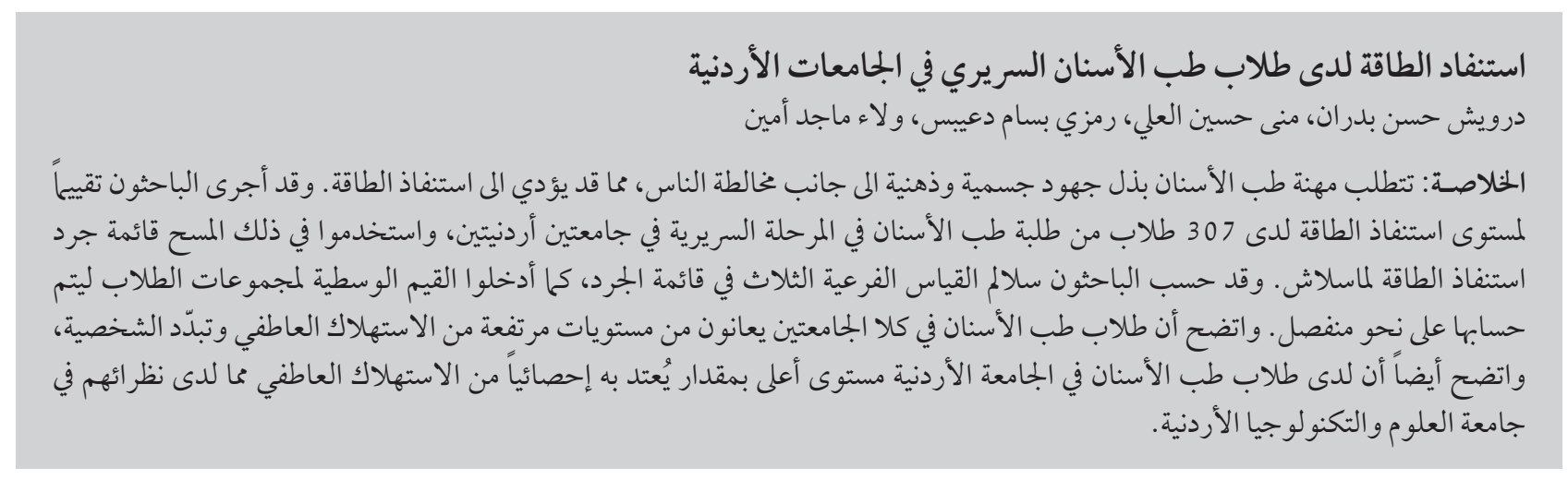

ABSTRACT Dentistry is a profession demanding physical and mental efforts as well as people contact, which can result in burnout. The level of burnout among 307 clinical dental students in 2 Jordanian universities was evaluated using the Maslach Burnout Inventory survey. Scores for the inventory's 3 subscales were calculated and the mean values for the students' groups were computed separately. Dental students in both universities suffered high levels of emotional exhaustion and depersonalization. The dental students at the University of Jordan demonstrated a significantly higher level of emotional exhaustion than their counterparts at the Jordan University of Science and Technology.

\section{L'épuisement professionnel chez les étudiants en dentisterie des universités jordaniennes}

RÉSUMÉ La dentisterie est une profession qui demande des efforts physiques et mentaux et un contact avec le public qui peuvent conduire à l'épuisement professionnel. Le niveau d'épuisement de 307 étudiants en dentisterie de deux universités jordaniennes a été évalué à l'aide de l'inventaire d'épuisement professionnel de Maslach. Les scores obtenus pour les trois sous-échelles de l'inventaire ont été calculés et les valeurs moyennes pour les groupes d'étudiants ont été déterminées séparément. Les étudiants en dentisterie des deux universités présentaient des niveaux élevés d'épuisement émotionnel et de dépersonnalisation. Les étudiants de l'université de Jordanie ont montré un niveau d'épuisement émotionnel nettement supérieur à celui de des étudiants de l'université jordanienne des sciences et de la technologie. 


\section{Introduction}

Dentistry is a profession demanding physical and mental effort as well as personal contact, which can result in a condition known as "burnout". Burnout is defined as "a syndrome of emotional exhaustion and cynicism that occurs frequently among individuals who do 'people-work' of some kind" [1]. It is characterized by 3 key aspects: emotional exhaustion (mental fatigue), depersonalization (psychological distancing from others) and reduced personal accomplishment $[2,3]$.

The rate of burnout among dentists and its effect on their lives have been previously investigated by many researchers [4-12]. Burnout can lead to early retirement and indifference to treatment outcomes and patients' conditions or needs [4]. The affected dentist also tends to avoid contact with people, including colleagues, patients, friends or even family. Burnout therefore obviously has serious detrimental effects on the profession as well as on society $[3,6]$.

Many researchers have studied the existence of stress among dental students $[2,7-12]$ and a few have studied the prevalence of burnout $[2,7-9,12]$. In a study aimed at testing the rate of burnout among German dental students at 3 universities [3], there were high scores for burnout regardless of the education system used. In a separate study, emotional exhaustion among dental students at 7 European schools was significantly higher than among medical students [2]. The perceived stress among dental students had been attributed to factors such as fear of failure [7], the load of academic and clinical work $[8,11]$, nonavailability in some colleges of materials for study and clinical training $[10]$ and performance pressure and self-efficacy beliefs [12]. It has been reported that students who demonstrated high levels of stress tended to show lower grades in clinical competency and contextual understanding [9].

The aim of this study was to determine the presence and level of burnout among clinical dental students at the 2 dentals schools in Jordan.

\section{Methods}

In Jordan, there are only 2 dental schools, the University of Jordan (UJ) and at the Jordan University of Science and Technology (JUST), both offering a bachelor degree programme.

The extent of burnout in 307 clinical dental students was assessed using the Maslach Burnout Inventory-Human Services Survey (MBI-HSS) [1]. The inventory comprises 22 items (phrases) measuring 3 subscales of burnout: emotional exhaustion ( 9 items), depersonalization (5 items) and personal accomplishment (8 items). Respondents score items on a scale from 1 to 4 indicating how often they encounter the item: 1 (never, rarely or a few times a year); 2 (once or a few times a month); 3 (once or a few times a week); 4 (daily). A high degree of burnout is reflected by high scores on the emotional and depersonalization subscales and low scores on the personal accomplishment subscale and vice versa. The 3 subscales, though related, are independent and therefore the degree of burnout is expressed by the scores of its 3 subscales rather than by a total score.

The MBI-HSS is an effective tool of proven reliability and validity in detecting the presence and assessing the degree of burnout in human services workers. The English version of the inventory was used since English is the teaching language in both the Jordanian dental schools.

The clinical students (4th and 5th year) of the dental schools at UJ ( $n$ $=83$ and $n=93$ respectively) and JUST ( $n=64$ and $n=67$ respectively) were asked to complete the inventory during a lecture at each of the universities during the 2 nd semester after the midterm examinations. The instructions were explained thoroughly to the students by the researchers. The responses were totally anonymous to ensure confidentiality. Prior to the survey, students were briefed on the objectives of the survey and the impact it would have on planning their study curriculum; the response rate was 100\%. Students were also asked to double-check their answers to ensure complete responses.

The score for each of the 3 subscales was calculated for each student from the sum of responses to the items in the subscale. Mean values were then calculated for each student group separately. Shapiro-Wilk test of normality indicated that the data were not normally distributed in many instances; consequently, nonparametric statistical tests were used to compare the results of the 4 student groups. Kruskal-Wallis 1-way analysis of variance (ANOVA) based on ranks was used in determining whether any significant differences existed among the groups. Multiple comparisons among the groups were performed using the Mann-Whitney rank sum test. Statistical analysis was carried out using SPSS, version 14.0, with the level of significance set at $P$ $<0.05$.

\section{Results}

The responses for the 4th and 5th year students of each university were described in terms of mean and standard deviation (SD). Cut-off values above which a subscale score was deemed high were obtained by correcting the values indicated in the MBI-HSS scoring key to compensate for the difference in scoring scale.

Female students at UJ had significantly higher mean scores on emotional exhaustion $(P<0.05)$ than their male counterparts in both the 4 th year [mean 
score 27.3 (SD 5.2) versus 23.2 (SD 4.6)] and 5th year [29.9 (SD 4.8) versus 26.7 (SD 5.5)]. No significant differences were found between males and females of either university in depersonalization or in personal achievement scores (Table 1).

Pairwise comparisons showed that the 4th year UJ students exhibited significantly higher degrees of burnout in all 3 subscales than their 5 th year counterparts $(P<0.05)$. On the other hand, no significant differences were found between 4 th and 5 th year students at JUST. Comparisons between the universities showed that UJ students had significantly higher degrees of emotional exhaustion than their counterparts at JUST $(P<0.05)($ Table 2$)$.

\section{Discussion}

Almost all of the students in the 4th and 5 th years in the 2 dental schools in the 2 Jordanian universities suffered

\begin{tabular}{|c|c|c|c|}
\hline \multicolumn{4}{|c|}{$\begin{array}{l}\text { Table } 1 \text { Scores on the } 3 \text { subscales of the } \\
\text { Services Survey for } 4 \text { student groups }\end{array}$} \\
\hline Student group/sex & $\begin{array}{c}\text { Emotional } \\
\text { exhaustion } \\
\text { (max. score 36) }\end{array}$ & $\begin{array}{l}\text { Depersonalization } \\
(\max . \text { score } 20)\end{array}$ & $\begin{array}{c}\text { Personal } \\
\text { achievement } \\
\text { (max. score 32) }\end{array}$ \\
\hline & Mean (SD) & Mean (SD) & Mean (SD) \\
\hline \multicolumn{4}{|l|}{ 4th year $U J$} \\
\hline Male & $23.2 *(4.6)$ & $7.0(2.3)$ & $26.7(2.9)$ \\
\hline Female & $27.3^{*}(5.2)$ & $7.0(2.6)$ & $25.2(4.6)$ \\
\hline All & $26.1(5.4)$ & $7.0(2.5)$ & $25.6(4.1)$ \\
\hline \multicolumn{4}{|l|}{5 th year $U$} \\
\hline Male & $26.7^{*}(5.5)$ & $8.1(2.9)$ & $23.6(4.6)$ \\
\hline Female & $29.9 *(4.8)$ & $8.2(2.6)$ & $22.6(4.0)$ \\
\hline All & $29.0(5.2)$ & $8.1(2.7)$ & $22.9(4.2)$ \\
\hline \multicolumn{4}{|l|}{ 4th year JUST } \\
\hline Male & $20.8(5.4)$ & $6.4(2.2)$ & $26.1(4.2)$ \\
\hline Female & $22.7(5.2)$ & $7.2(2.3)$ & $26.5(4.0)$ \\
\hline All & $21.8(5.4)$ & $6.9(2.3)$ & $26.0(4.6)$ \\
\hline \multicolumn{4}{|l|}{ 5th yearJUST } \\
\hline Male & $20.8(4.8)$ & $7.5(2.3)$ & $24.9(4.6)$ \\
\hline Female & $22.7(4.9)$ & $7.3(2.3)$ & $26.3(4.0)$ \\
\hline All & $21.0(4.9)$ & $7.6(2.1)$ & $24.9(5.0)$ \\
\hline
\end{tabular}

${ }^{*} P<0.05$ between males and females of the same student group.

$S D=$ standard deviation; $U J=$ University of Jordan; JUST = Jordan University of Science and Technology. high degrees of emotional exhaustion. In a previous study it was reported that only $22 \%$ of the surveyed students from 7 European dental schools had high degrees of emotional exhaustion [2]. The scores of emotional exhaustion determined in this study were extremely high, especially those of the UJ students. Even the relatively lower scores attained by the JUST students were still higher than those reported by the European study [2]. The cause of the high levels of emotional exhaustion shown by the Jordanian dental students may be related to the pressures of studying, examinations, competition and fulfilment of the minimum clinical requirements in addition to the primary cause of direct contact with patients. Further investigations to determine the possible factors related to this problem and its possible causes are necessary and of significant importance.

Comparisons between the 2 dental faculties showed that UJ students had significantly higher scores of emotional exhaustion than JUST students. tion level in those students.

Clinical sessions were longer and less frequent in JUST dental faculty (data not presented). Thus, UJ students may have been more stressed trying to finish their procedures in time. Furthermore, having more clinical sessions per week means a higher level of patient contacts, which in turn is likely to increase the level of emotional exhaustion.

The availability of the staff during the clinical sessions might also have played a role. In JUST, the staff-tostudent ratio was very favourable for both the learning experience and the student's mental health. As each clinical instructor handles fewer students, the student receives a longer time and better attention from the staff. Moreover, JUST provides an allied dental sciences programme whose students assist the clinical dental students during their sessions, putting 4-handed dentistry into practice. The Faculty of Dentistry at UJ 


\begin{tabular}{|c|c|c|c|}
\hline \multicolumn{4}{|c|}{$\begin{array}{l}\text { Table } 2 \text { Significance of differences (Mann-Whitney rank sum test) among students } \\
\text { for the } 3 \text { subscales of the Maslach Burnout Inventory-Human Services Survey }\end{array}$} \\
\hline \multirow{2}{*}{$\begin{array}{l}\text { Compared groups, } \\
\text { year and university }\end{array}$} & \multicolumn{3}{|c|}{$P$-value } \\
\hline & $\begin{array}{l}\text { Emotional } \\
\text { exhaustion }\end{array}$ & Depersonalization & $\begin{array}{c}\text { Personal } \\
\text { achievement }\end{array}$ \\
\hline 4th $\mathrm{UJ}$ versus 5 th $\mathrm{UJ}$ & $<0.001$ & 0.005 & $<0.001$ \\
\hline 4th JUST versus 5th JUST & 0.466 & 0.105 & 0.305 \\
\hline 4th UJ versus 4th JUST & $<0.001$ & 0.914 & 0.422 \\
\hline 5th UJ versus 5th JUST & $<0.001$ & 0.270 & 0.014 \\
\hline
\end{tabular}

UJ = University of Jordan; JUST = Jordan University of Science and Technology.

does not offer such programmes; this has obliged the students of the UJ to find their own patients and to handle them entirely by themselves

Depersonalization may be the most critical aspect of burnout in a health care profession such as dentistry. Perceiving the patient as an impersonal object rather than a human being might result in detrimental negligence in treatment procedures and disregard of the psychological aspects of treating patients. In both dental schools 5 th year students had significantly higher scores of depersonalization than 4th year students. No significant differences were found between students of the 2 schools in the same academic level. These findings might suggest that depersonalization increases with increased patient contact. Longitudinal studies are necessary to confirm this suggestion, but increasing the students' as well as the instructors' awareness of such a problem is imperative to avoid further development of the problem in the future clinical career of the students.

High scores of personal achievement mean more involvement with the patients and more satisfaction with the profession and consequently, lower degrees of burnout. The lower mean scores of personal achievement in 5th year students at UJ compared with 4th year students should be viewed as another sign of increasing burnout which was related to increased patient contact in terms of frequency and duration (data not presented). This scale of burnout is extremely important and should be training period of dental students and even after their graduation to ensure that feelings of lack of personal achievement have diminished. closely monitored during the clinical

\section{Conclusions and recommendations}

The findings of this study indicated that dental students at Jordanian universities suffered considerable degrees of burnout. Dental students as well as instructors should be informed about burnout and its elements to increase their awareness of the problem. Analytical studies targeting students' health and psychology should be carried out regularly to determine the causes and factors related to the high degree of burnout among dental students.

\section{Acknowledgements}

The authors express their sincere gratitude to the dental students of the universities who participated in this survey and to the deans of the 2 faculties for their interest in the study and for providing access to lectures. Special thanks go to Ms Ikram Tamimi of the Centre for Educational Development for her invaluable assistance in tabulating the data and organizing the results. The authors would also like to express their thanks to Dr Hanan Jafar of the Faculty of Medicine and Dr Ammar Kassab, intern and research fellow at the Faculty of Dentistry for their efforts and assistance in conducting the survey.

\section{References}

1. Maslach C, Jackson SE. The measurement of experienced burnout. Journal of organizational behaviour, 1981, 2:99-113.

2. Humphris $G$ et al. Psychological stress in undergraduate dental students: baseline results from seven European dental schools. European journal of dental education, 2002, 6:22-9.

3. Pöhlmann K et al. Stress, burnout and health in the clinical period of dental education. European journal of dental education, 2005, 9:78-84.

4. Rada RE, Johnson-Leong C. Stress, burnout, anxiety and depression among dentists. Journal of the American Dental Association, 2004, 135:788-94.

5. Felton JS. Burnout as a clinical entity--its importance in health care workers. Occupational medicine, 1998, 48:237-50.

6. Osborne D, Croucher R. Levels of burnout in general dental practitioners in the south-east of England. British dental journal, 1994, 177:372-7.
7. Acharya S. Factors affecting stress among Indian dental students. Journal of dental education, 2003, 67:1140-8.

8. Naidu RS et al. Sources of stress and psychological disturbance among dental students in the West Indies. Journal of dental education, 2002, 66:1021-30.

9. Sanders AE, Lushington K. Effect of perceived stress on student performance in dental school. Journal of dental education, 2002, 66:75-81.

10. Sofola O, Jeboda S. Perceived sources of stress in Nigerian dental students. European journal of dental education, 2006, 10:20-3.

11. Al-Omari WM. Perceived sources of stress within a dental educational environment. Journal of contemporary dental practice, 2005, 6:64-74.

12. Polychronopoulou A, Divaris K. Perceived sources of stress among Greek dental students. Journal of dental education, 2005, 69:687-92. 